\title{
South African Psychiatry - charting a way forward
}

South African Psychiatry witnessed a recent event, that by all accounts is unprecedented in low and middle income countries: a national mental health summit, this according to one of the speakers at the summit- Shaker Saxena, of the World Health Organization. South Africa is divided into 9 provinces and prior to the national summit, provincial summits were held in order to identify issues and develop position statements for the national summit i.e. the process was systematic. Between these various summits, the South African Society of Psychiatrists (SASOP) convened a special meeting of state employed psychiatrists to consider a range of matters relevant to psychiatric practise in the state sector - this in order to not only inform the national summit but to provide input into the National Mental Health Policy which is currently work in progress, and represents the development of a policy for mental health that will be officially endorsed. In essence, a series of events which speak to a collaborative approach to charting a way forward for South African Psychiatry. Given the understanding that there can be "no health without mental health" (cited by Flisher and Lund', from The Lancet series on mental health ${ }^{2}$ ) - this summit was a clear signal of intent from the South African government.

South Africa has a progressive constitution and bill of right $s^{3}$ together with one of the most recently promulgated pieces of legislation related to mental health in Africa ${ }^{4}$ i.e. the Mental Health Care Act (No. 17 of 2002). ${ }^{5}$ Whilst in terms of the Constitution government has an obligation to facilitate the progressive realisation of rights - which include access to health care - the Mental Health Care Act (MHCA) which is aligned with the Constitution states that provision of care is ultimately within the context of resources. Hence, a critical issue is resources. The assumption might be that this is purely financial. It should be noted that South Africa spends over 8\% of its gross domestic product (GDP) on health - comparing favourably with developed nations. ${ }^{6}$ Funding certainly drives services, but ultimately it is people who are responsible for both developing and delivering the service. Such people are not only clinicians, but also administrators and politicians. Whilst not directly responsible for delivering service, an important component of service delivery comprise advocacy groups - which whilst traditionally might be viewed as non-governmental organisations, also includes family

\section{Correspondence}

Prof CP Szabo

email: christopher.szabo@wits.ac.za members and patients themselves as well as clinicians, administrators and politicians. In short, service delivery is a collective responsibility with each component contributing to the whole. The national mental health summit represented the coming together of all concerned and the last speaker at the opening plenary saw a rehabilitated substance abuser, now actively involved in community based rehabilitation efforts, speak frankly of their struggle, their involvement in community initiatives as well proposing interventions at that level- engaging directly with the Minister of Health in the audience.

The challenge is to convert funding into appropriate, quality services that are equitably spread across the country. Some may view the aforementioned meetings as nothing more than "talk shops" that are long on rhetoric and short on delivery. The challenge is to prove such sentiment wrong. Time will tell. Certainly the South African Provincial and National Departments of Health, the South African Society of Psychiatrists as well as participants at all of the meetings are to be congratulated for their efforts As part of this process, the African Journal of Psychiatry in partnership with the South African National Department of Health - intends publishing a supplement to a forthcoming edition of the Journal dedicated to presentations at the national mental health summit. Such content will hopefully have lessons and provide guidance not only for South Africa, but also Africa.

\section{Christopher P. Szabo} Editor-in-Chief

\section{References}

1. Flisher A, Lund C. Mental health policy in Africa. African Journal of Psychiatry 2010; 13(2): 81-83.

2. Lancet Global Mental Health Group. Global Mental Health- $A$ call for action. Lancet 2007; 370: 1241-1252.

3. Constitution of the Republic of South Africa, 1996; Chapter 2 Bill of rights, section 27, Health Care, Food, Water and Social Security. http://www.info.gov.za/documents/constitution/1 996/96 cons2.htm\#27 accessed 26th March 2012.

4. 4. Flisher A, Lund C. Resources for mental health services in Africa: a situation analysis. In Ndetei DM, Szabo CP, eds Contemporary Psychiatry in Africa: a Review of Theory, Practice and Research. Acrodile Publishing, Nairobi, Kenya. 2011: 1-24.

5. 5. Mental Health Care Act, 2002. Government Gazette, Vol. 449, No. 24024, 6 November 2002. Cape Town, Republic of South Africa.

6. The Economist. Pocket World in Figures 2007 Edition. Profile Books Ltd, London, UK. 